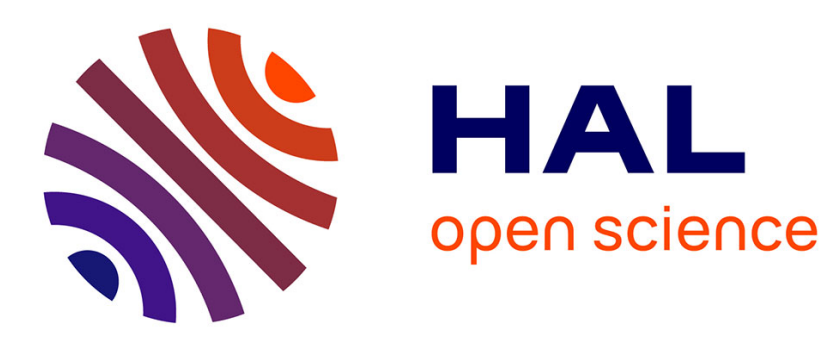

\title{
Attitudes towards genetics: a case study among Brazilian high school students
}

Luisa Massarani, Ildeu de Castro Moreira

\section{To cite this version:}

Luisa Massarani, Ildeu de Castro Moreira. Attitudes towards genetics: a case study among Brazilian high school students. Public Understanding of Science, 2005, 14 (2), pp.201-212. 10.1177/0963662505050992 . hal-00571061

\section{HAL Id: hal-00571061 \\ https://hal.science/hal-00571061}

Submitted on 1 Mar 2011

HAL is a multi-disciplinary open access archive for the deposit and dissemination of scientific research documents, whether they are published or not. The documents may come from teaching and research institutions in France or abroad, or from public or private research centers.
L'archive ouverte pluridisciplinaire HAL, est destinée au dépôt et à la diffusion de documents scientifiques de niveau recherche, publiés ou non, émanant des établissements d'enseignement et de recherche français ou étrangers, des laboratoires publics ou privés. 


\title{
Attitudes towards genetics: a case study among Brazilian high school students
}

\author{
Luisa Massarani and Ildeu de Castro Moreira
}

The objective of our study was to investigate young people's attitudes towards modern genetics and biotechnology. Quantitative and qualitative studies were conducted among high school students in Rio de Janeiro. These included a survey of students in nine public and private schools as well as focus groups for a complementary analysis of their attitudes and perceptions with respect to these subjects. We observed that, in general, students are relatively well informed about some of the main issues related to the applications of genetics. In their assessment of the utility, the potential risks, and the need for encouragement of the different techniques used in genetic manipulation, they were able to make clear distinctions between the different purposes of each technique. Most students believed that transgenic food could be useful and that it should be encouraged, but they were also aware that there were risks involved. Furthermore, the students were strongly supportive of the labeling of transgenic food.

\section{Introduction}

The issue of people's attitudes towards modern genetics and biotechnology is arousing growing interest in many countries and it is the object of many quantitative and qualitative studies. Surveys have been carried out in the United States (National Science Foundation, 2002), European countries (Gaskell and Bauer, 2001; Cheveigné et al., 2002) and Canada (Einsiedel and Medlock, 2001). Other studies focused on specific groups, such as the one examining young students in schools in the United Kingdom (Lewis and Wood-Robinson, 2000). In the field of biotechnology, specific issues have been considered, such as perceptions of human genetic information and agricultural biotechnology (Human Genetics Commission, 2001; Shanahan et al., 2002).

In Brazil, very little has been done to analyze the different aspects of public understanding of science, and, in particular, people's attitudes towards genetics and biotechnology. One of the rare relevant studies investigating public attitudes and opinions towards general aspects of science and technology was a national survey conducted in 1987 by CNPq, the National Council of Scientific and Technological Development (Alves and Tolmasquim, 1987). In the field of biotechnology, especially with respect to genetically modified (GM) organisms, two later surveys are noteworthy. These surveys were carried out 
by the IBOPE (Brazilian Institute on Public Opinion and Statistics), in 2001 and 2002, and explored public opinion on GM food.

The first survey by IBOPE (2001) on transgenic crops showed that 74 percent of Brazilians preferred non-transgenic food, while 14 percent supported the use of transgenic food. ${ }^{1}$ Those with higher incomes were slightly more likely to reject GM food than were those with lower incomes: 85 percent belonging to classes $\mathrm{A}$ and $\mathrm{B}$ (upper economical classes) rejected GM food, compared to 77 percent in class $\mathrm{C}$ and 68 percent in classes D and E . Similarly, the higher the level of education, the higher the percentage of people who preferred non-transgenic food; for example, 85 percent of those with university level education opposed GM food. This poll also showed that a large majority-nine in ten adults - thought that food with genetically modified ingredients should be identified as such on the label. Support for food labeling increased with higher levels of education and income. The survey also found that two-thirds of the respondents were of the opinion that transgenic crops should be prohibited until all the important questions concerning the risks involved have been adequately addressed. The results of the 2002 IBOPE survey were very similar to those of the 2001 survey.

These national surveys considered the question of genetically modified food because of the issue's prominence in Brazil in the past few years. The country is one of the biggest producers of grains and most of this production consists of conventional rather than transgenic grains. Currently, Brazilian law does not allow the production of transgenic crops and new legislation on this issue is currently being discussed in the National Congress. In 2003, provisional legislation allowing the sale of a large quantity of illegally grown transgenic soybean raised a great deal of controversy throughout the country.

The objective of the present study was to investigate young people's attitudes towards modern genetics and biotechnology. We studied high school students of nine public and private schools in Rio de Janeiro, through questionnaires and focus groups. Brazil has a large population, and there are significant regional differences and large social inequalities in many areas-including scientific education and access to information. Our case study investigated high school students from a single metropolitan area only. Hence, the attitudes of these students will not necessarily reflect the attitudes of young people in the country as a whole.

The current research is part of a wider project for the investigation of public understanding of science in Brazil, which includes the analysis of press coverage of biotechnology, university and high school students' attitudes towards general aspects of science, and their knowledge of some specific scientific content (Massarani, 2001). ${ }^{2}$

\section{Methodology}

We examined students' attitudes about the impact of various biotechnological applications in society, employing both quantitative (questionnaire) and qualitative (focus group) methods. Questionnaires were used to explore students' current attitudes towards biotechnology, while focus groups were employed to analyze how they think and why they think that way, i.e. how their knowledge and opinions are shaped by the different contexts of which they are part.

\section{Quantitative approach}

With our questionnaire, we investigated the students' views about the following applications of modern genetics: 
Genetic modification of organisms. We examined whether there were differences in the approval of this technique when applied for different purposes. We assessed three types of application: in the food industry (production of pest-resistant crops and GM food), in the health sector (production of medicines/vaccines and organs for transplants) and in basic research (genetic modification of animals for laboratory research).

Genetic manipulation of the embryo. Here again, we investigated whether there were differences in the attitudes towards the different uses of the same basic technique. We compared the students' attitudes to the manipulation of embryos for aesthetic purposes (i.e., ensuring that the baby will have specific physical characteristics such as eye and hair color) to that for health purposes (i.e., ensuring that the baby will not develop genetic diseases).

Genetic testing by individuals versus testing by insurance companies. Furthermore, we sought to find out whether there was a change in the number of respondents that approved genetic testing for the premature detection of potential diseases, depending on whether these techniques were used by parents, or by insurance companies.

The questionnaire was in part based on the Eurobarometer 1996 survey (Durant et al., 1998). ${ }^{3}$ Students were asked to what extent they agreed or disagreed with each of the applications with respect to (1) their actual use, (2) their benefits to society, (3) the risks involved in their application, (4) their moral acceptability and (5) whether they should be encouraged. The following response options were provided: "strongly agree," "somewhat agree," "somewhat disagree," "strongly disagree," and "don’t know."

We analyzed 610 questionnaires filled out by students in the second grade of secondary school (370 from public schools and 240 from private schools). Our study incorporated different types of school in Rio de Janeiro, namely: (1) three schools that were funded by the government, did not charge fees, and were located in poor areas; (2) two schools that were government-funded, did not charge fees, but were located in socially and economically more privileged areas, although students came from a variety of economic backgrounds; (3) three private schools that charged monthly fees, were located in socially and economically privileged areas, and concentrated students of higher purchasing power; (4) one school that, despite being situated in a poorer area, charged a monthly fee, and, hence, accommodated students mainly from the local elite. The questionnaires included closed questions as well as space for additional comments.

\section{Qualitative approach}

In the qualitative phase of the research, we subjected some of the questionnaire data to a more in-depth analysis by means of focus groups. This allowed us to assess the students' perceptions of the relative importance of the different arguments presented to them and of the issues raised by the students themselves in the additional comments section of the questionnaires.

We organized six focus groups, each of which consisted of about five students from the same school. ${ }^{4}$ The schools were selected in such a way that students from different social and economic backgrounds within the city would be represented. There was a broad interest in participating in the focus groups. The participants were chosen randomly from the students who had indicated their willingness to participate. However, we cannot rule out that those students who agreed to participate in the focus groups were more interested in science issues than the average student in their respective schools was. Yet, it should be stressed that a broad interest in modern genetic issues was also observed in most of the questionnaires. 
The starting point for the focus group discussions was a compilation of excerpts of the 1997 American movie GATTACA. We used an abridged (nine-minute) version of the movie, showing key issues to get the debate in the focus groups going. The movie depicts a society in which human beings are being generated from embryos by means of in vitro genetic selection. This fictitious society strives for "genetic perfection," i.e. the elimination of diseases and other characteristics considered undesirable, such as baldness and alcoholism.

Although this movie is a great tool for stimulating debate among the students, it has its own agenda; it strongly criticizes the fictitious society presented, where there is prejudice against human beings who are conceived naturally (i.e., without the use of genetic manipulation), by pointing out the difficulties these people would face in such a context. This biased view may have contributed to the students' critical attitudes towards human genetic manipulation observed in the focus groups. However, the focus groups took place after the students had answered the questionnaires, in which they had already shown a strong critical position with regard to different aspects of genetic embryo selection and expressed their concern about its ethical and risk aspects.

After having shown the movie, we started the discussion using a list of core questions on the main issues. ${ }^{5}$

\section{Quantitative research}

\section{Results of the quantitative analysis}

A synthesis of the main results of the questionnaire data is presented in Table 1. The following key patterns can be identified:

1. While GM food is seen to be useful by two-thirds of the students, more than threequarters of the respondents view these types of applications as risky and about a third do not think it is morally acceptable. Applications to crops are more likely to be

Table 1. High school students' attutides towards new genetic technologies (percent)*

\begin{tabular}{|c|c|c|c|c|c|c|c|c|}
\hline \multirow[b]{2}{*}{ Item } & \multicolumn{2}{|l|}{ Utility } & \multicolumn{2}{|l|}{ Risk } & \multicolumn{2}{|c|}{ Moral acceptability } & \multicolumn{2}{|c|}{ Encouragement } \\
\hline & Agree & Disagree & Agree & Disagree & Agree & Disagree & Agree & Disagree \\
\hline GM food & 66 & 29 & 78 & 16 & 55 & 35 & 56 & 32 \\
\hline GM crops & 81 & 14 & 63 & 26 & 65 & 24 & 65 & 23 \\
\hline $\begin{array}{l}\text { GM medicines and } \\
\text { vaccines }\end{array}$ & 87 & 8 & 62 & 28 & 74 & 16 & 78 & 13 \\
\hline $\begin{array}{l}\text { GM animals for laboratory } \\
\text { research }\end{array}$ & 74 & 21 & 68 & 25 & 48 & 44 & 57 & 32 \\
\hline $\begin{array}{l}\text { GM animals to produce } \\
\text { organs for transplant }\end{array}$ & 72 & 22 & 78 & 15 & 50 & 41 & 62 & 17 \\
\hline $\begin{array}{l}\text { Genetic tests to } \\
\text { prematurely detect diseases }\end{array}$ & 89 & 8 & 40 & 50 & 79 & 14 & 81 & 12 \\
\hline $\begin{array}{l}\text { Genetic tests by insurance } \\
\text { companies }\end{array}$ & 46 & 47 & 55 & 30 & 42 & 49 & 41 & 56 \\
\hline $\begin{array}{l}\text { Embryo manipulation to } \\
\text { prevent diseases }\end{array}$ & 69 & 15 & 73 & 17 & 47 & 42 & 56 & 33 \\
\hline $\begin{array}{l}\text { Embryo manipulation for } \\
\text { aesthetic purposes }\end{array}$ & 23 & 71 & 69 & 19 & 22 & 71 & 22 & 68 \\
\hline
\end{tabular}

* In this table, the responses for "strongly agree" and "somewhat agree" have been lumped together as "agree"; likewise, those for "strongly disagree" and "somewhat disagree" have been combined into "disagree." 
encouraged by about two-thirds, since a smaller majority sees this application as risky (63 percent) and less than a quarter see GM crops as morally unacceptable.

2. With regard to medical applications, GM applications tend to be viewed more positively, with a large majority of students seeing genetic testing to detect diseases as useful, morally acceptable, and to be encouraged; only a minority perceives risks for this application. However, when carried out by insurance companies, these tests are discouraged by a majority of students.

3. GM applications designed to produce medicines and vaccines were also viewed as useful and morally acceptable; consequently, a large majority is more likely to encourage this application than food or crop applications. When applied to animals in order to produce organs for transplants on the other hand, the perceived risks tend to be more prominent, hence reducing the students' willingness to encourage this application. Less likely to be encouraged are embryo manipulations to avoid disease, with students split on the moral acceptability of this practice. The least desired medical application is embryo manipulation for aesthetic reasons. Thus, while medical applications directed at disease are viewed more positively than food and crop applications, the students do not view all medical applications alike.

Overall, the patterns observed in our questionnaire data are consistent with the findings in the Eurobarometer survey among Europeans (Gaskell et al., 1999, 2000; Gaskell and Bauer, 2001).

\section{Comparisons with other studies}

Although two earlier Brazilian surveys (IBOPE, 2001, 2002) sampled different pools of respondents and used different questions, some aspects of these studies are comparable to our own study. The first IBOPE (2001) poll found that, among all age groups, people between the ages of 16 and 24 years-i.e., those in the same age range as the students in our study - were the group that showed the lowest rejection rate towards transgenics. In this age group, 68 percent preferred non-transgenic products, compared to 79 percent for 25-34 year olds, 76 percent for 35-49 year olds, and 72 percent for those 50 years of age and older. As far as labeling of GM food is concerned, the only group that showed a lower approval rate than the people under 25 years of age was that of people over 50, with 83 percent; for all other age groups, including the one consisting of young people, the figures were in the 93-94 percent range (IBOPE, 2001).

In the same poll, most of the people under 25 years of age (67 percent) believed that transgenic crops should be prohibited until all the important questions around the risks involved were adequately addressed. For the other age groups, the numbers were 69 percent ( 25 to 34 years), 70 percent (35 to 49 years) and 62 percent (50 years and over).

Among the students in our survey, 66 percent agreed that the use of biotechnology in food is socially useful, for example by increasing the protein content or the size or by changing the flavor; in the case of using biotechnology for increased pest resistance in cultivated plants, the percentage increases to 81 percent. However, there was a strong perception that there were risks associated with this technology; this was the case with 78 percent of respondents for the first application and 63 percent for the second. With regard to the first application, 56 percent supported its encouragement, while the approval rate was 65 percent for the second one.

The results of our own research corroborate the finding in the IBOPE polls that, in general, young people are more open to technological innovations than the other age groups are. Both studies show that a significant number of young people think that the genetic 
engineering of food is useful and should be encouraged, but that there are risks involved. The students would prefer that transgenic crops not be grown until these risks can be adequately addressed. Furthermore, they would prefer non-transgenic food, but if transgenic food were to be put on the market, they think it should be labeled.

Another aspect that deserves our attention is the relationship between the level of education on the one hand and the acceptance of transgenic food on the other. Some researchers have suggested that people do not accept transgenic food because they do not have a sufficient educational background to understand the benefits of new technologies (e.g., Oda and Soares, 2001). Yet, the IBOPE surveys show that the simplistic assumption that there is a direct link between the degree of education and the degree of approval for transgenic food is not sustainable. Durant et al. (1998) have also linked education level to the degree of approval of transgenic food, but in a different way. Their results, based on studies carried out in 17 European countries, suggest that people with higher knowledge levels are more likely to express a definite opinion about biotechnology. However, this does not necessarily imply a positive opinion. As these authors explain: "knowledge is one of the resources that contribute to the formation of opinions, but those opinions may be positive or negative" (Durant et al., 1998: 200).

\section{Qualitative research}

The main findings from the focus groups are consistent with the results from the questionnaires (see Massarani, 2001, for details). Although, in this case study, we focused on genetic issues per se, the students made general comments on science and scientists as well. First, we will address the students' arguments on the main issues presented to them in the focus groups, and then we follow with a discussion of other comments made by the students.

\section{General characteristics of the focus groups}

One of the salient features of the focus groups was the great interest of students in a wide variety of issues related to genetics and their implications for society. Although in several instances the students did not have qualified information on the subject, they nevertheless reflected on these issues and expressed themselves in a non-superficial manner, considering both positive and negative aspects of the issue at hand. In general, they did not express the same attitude typical of most of the press coverage in Brazil, which commonly consists of simplistic positions that do not reflect the different aspects and the complexity of these subjects (Massarani et al., 2003a, 2003b).

Analysis of the focus group discussions confirmed the observation made in the analysis of the questionnaires that most students were able to make clear distinctions between the different purposes of each technique used in genetic manipulation. This was reflected in their assessment of the utility, the potential risks, and the need for encouragement of the different techniques. For example, there is a general positioning against the use of the genetic selection of embryos for aesthetic purposes and against genetic tests that might induce discrimination among people (by the labor market or by insurance companies, for example). In other cases, especially those concerning medical use, the students' attitudes were more favorable, although they were aware that risks remain an important issue.

In general, students emphasized risks resulting from the potential abuse of techniques developed in scientific research, particularly in biotechnology. They also warned about the difficulty of establishing boundaries between what should and what should not be allowed. 
Furthermore, they stressed that, even if these boundaries could be established and new technologies were applied the way they were intended, some side effects could still arise. For example, they indicated that a technique that would allow the reduction or even the complete elimination of a disease might lead to overpopulation of the planet. Hence, the students emphasized the need for taking careful steps before putting genetic technologies to use. They also pointed out the possibility that the benefits of biotechnology would only be available to the elite. Prejudice and social discrimination that would possibly result from this were criticized in all focus groups.

\section{Themes and argumentation used by students}

The use of focus group methodology allowed the students to discuss the issues at hand from different perspectives and with a wide scope of arguments. Topics included the genetic selection of embryos, the role of genes versus that of the environment (including social, cultural, educational and other issues) in constituting individual characteristics, and genetically modified organisms.

In the case of genetic manipulation, the positive factors pointed out were mostly related to medical uses, such as strategies to avoid genetic diseases. Another advantage mentioned was the possibility of helping to prevent species from becoming extinct. Among the negative aspects mentioned were the potential risks involved and the discriminatory effects that it could induce. Another possible impact of genetic manipulation that was indicated was related to the possibility of modifying the nature, and hence the results, of the Olympic Games owing to the enhancement of the physical strength of athletes. For many students in the focus groups, the dark scenario of GATTACA already exists, although on another scale. An example of that would be the fact that health insurance companies already trace people's medical history - in order to establish the likelihood that a client will develop certain diseases - and the insurance premiums are based on these results.

Another objection mentioned to the genetic selection of embryos produced in laboratories was the resulting homogeneity of a species' DNA, thereby compromising the interspecific variability and heterogeneity fundamental for the survival of the species. For example, a species composed of individuals with homogeneous characteristics would be more susceptible to new diseases that might eventually appear. The fact that commercial and financial interests are involved in the new genetic technology was also seen as an issue of concern. In many cases, this led the students to approve of genetic selection only for medical applications.

Human cloning was a bridge to discuss the roles played by genes and by the environment in forming individual characteristics. Many students stated that the cloned human would not be a perfect copy of the original individual, since they considered environmental factors to be responsible for shaping the personality of the clone. A few participants in the focus groups even thought that, secretly, clones have already been created. The students considered human cloning a danger for society and they had many doubts about the possible implications of this procedure. A lively ethical debate ensued in one group when some students defended the practice of cloning humans as a natural result of the advancement of science. Some groups pointed out the need for establishing limits to cloning and for the development of a code of ethics for scientific research.

One of the subjects of great importance to the students revolved around the shortage of donor organs, which results in premature death for many patients on waiting lists. Some groups discussed alternative solutions to the use of human donor organs, ranging from cloning to the development of genetically modified pigs for human xenotransplantation. Cloning related to transplant organs was generally seen in a positive light. 
Transgenic food was one subject in which students of almost all groups showed great interest. They discussed-sometimes on their own initiative-environmental, economical and social aspects related to the issue, as well as the need for extensive research as a prerequisite for releasing transgenic food into the marketplace. Environmental implications, associated economic interests, and the importance of labeling were widely mentioned.

All focus groups mentioned the risks of transgenic technologies, but many advantages were also brought up, such as increased productivity (with a consequent reduction in price); elimination of world hunger; increased resistance of food to pests and spoiling; production of food with enhanced taste and appearance; and production of food containing ingredients that protect against disease. Those students who neither saw advantages nor condemned transgenic technologies argued that GM products would do you no good, but they would not harm you either; they are as unhealthy and unnatural as most currently available foods that are produced with agrochemical substances. The following disadvantages of transgenic food were identified: unpredictable health risks, resulting from the fact that it is not natural or from the fact that we do not know what is being changed; possible environmental imbalances; possible deterioration of the quality of life for small farmers, owing to a predominance of large companies; the belief that it would not solve the world hunger problem, since this can only be solved by implementing economic and political changes that benefit developing nations, rather than through technological means.

Some students did not understand that each genetically modified crop or food is designed with a specific objective in mind-e.g., therapeutic properties, increased protein concentration, increased tolerance for herbicides, increased resistance to rotting or to insect pests-and that different objectives often require different techniques. They seem to perceive GM food as being part of one broad, single category. Another misconception is that all genetically modified crops are sterile, supposedly forcing farmers to buy new seeds for every crop.

With respect to how important the students thought it was to establish limits to scientific research and for scientific research to be guided by ethical principles, the data from the focus groups were in agreement with those from the questionnaires. Many students favored restricting scientific research itself, while others believed that only the applications of that research should be controlled. Several students stressed the importance of considering the social impact even in the developmental stages of scientific research, while others thought that establishing ethical guidelines for scientific research would be pointless since it would be likely that scientists ignore them, i.e., that they would perform research even without societal approval. The students also pointed out that, even when scientists would feel obliged to respect the rules, they themselves might be unaware of the possible consequences of their research. There was a general recognition that the regulation of scientific research was very controversial and that the implementation of control procedures was a complicated issue.

With regard to the question of who should be responsible for establishing the rules guiding scientific research, some students thought that a scientists' committee should be in control, while others believed that only the government should execute this control, as it represents the general interests of society. Still others preferred a committee made up of both government officials and representatives of different segments of society. The discussions on the subject of establishing a social control mechanism were quite superficial, perhaps due to a lack of confidence in governmental institutions and/or to the recognized weakness of Brazilian society and corporate governance. Students were not aware of any existing control mechanisms, such as those developed by the National Technical Commission on Biosafety (CTNBio), which is currently the agency in charge of overseeing scientific research in this field in Brazil.

The focus groups not only involved discussion on the issues specified in the script, but also addressed issues that were raised by the students themselves, such as experiments on 
animals, abortion, eugenics and emerging viruses. There was general agreement that animal experiments were important, but some students pointed out that they should only be carried out if there was a real need for them and if animal suffering would be minimized as much as possible. Almost all groups mentioned some of the modern genetic icons: transgenic tomatoes, the mouse that grew a human ear on its back, and Dolly the sheep. There were spontaneous references to the Human Genome Project, and to the announcement by Zavos and Antinori that the technology required for human cloning was already available-both subjects that received ample coverage in the media at the time.

In some groups, instead of discussing the issues around genetic manipulation in a general way, we introduced topics pertinent to the students' day-to-day life by presenting them with concrete situations they might come across. In the case of genetically modified food, for example, we asked them directly if they would eat such food. Some students said they were against transgenic food but would eat it if they were hungry. Another example concerns the use of genetic selection of embryos when deciding to have a baby. Some students had different opinions, depending on whether the issue was discussed in general terms or whether hypothetical scenarios of real situations were presented. A number of students approved the genetic manipulation of embryos in order to ensure that babies would not develop any diseases, yet some of them would rather not use such a technique on their own children. Others were against this technique, but would do anything to prevent their babies from getting diseases. Some groups raised the possibility of a person changing his/her point of view on a delicate issue when going through personal problems. In one group, there was a passionate discussion on how personal issues may interfere when decisions have to be made by society as a whole.

This type of question draws attention to an important observation, namely that a person's attitudes may differ, based on whether he/she considers the issue of concern from an individual or from a collective perspective. The public, in our case young people, cannot be seen as a group of individuals who simply try to defend their interests. People's attitudes may vary - that is, their restrictive criteria may be altered-when implications that are being considered are more general. For example, they might be against the use of a certain technique because of the collective risks it might involve; alternatively, when the issue has repercussions for a serious personal or family problem, they might, in fact, approve of it.

It is important to note that the students' attitudes will not necessarily be expressed in the actual behaviors they exhibit, since these attitudes are a measure of the student's feelings and preferences towards an issue at one particular point in time. Their actual behavior would also depend on the specific context of use of the genetic technique, as well as on subjective norms, such as the beliefs about other people's viewpoints on one's own performance (Potter and Wetherell, 1987).

\section{Final considerations}

Some additional items were included in the questionnaire to allow us to assess to what extent the high school students we studied were interested in science and had a positive outlook on scientific activity in society in general. Ninety percent of the respondents indicated an interest in science ( 37 percent high, 53 percent moderate). The number of students who have a positive image of scientists is almost as high (81 percent). Almost half of the students thought that the advantages of doing scientific research outweighed its disadvantages, while 7 percent disagreed and 32 percent believed that the pros and cons were in balance.

Concerns about the influence of economic and political factors on scientists' work and about the possibility that scientific applications would be used for the wrong purposes were 
frequently expressed, as were worries related to nuclear weapons and human cloning. The importance of assessing the risks involved in scientific research was pointed out by a considerable number of students. However, we did not analyze what specific conception of risk was adhered to by the students. A risk assessment by professionals working in this field might be very different from one by the general public, because of the differences in priorities and values between both groups (Wertz et al., 1986).

Many students mentioned the possibility of scientific research evading the control of the scientists, with consequences not initially foreseen. The cautious position of these students towards science was also reflected in the statement of those who suspected that the scientific community was not transmitting all its information to society, particularly information relating to the negative consequences of scientific research. However, this critical attitude is not a reflection of a more general attitude against scientific progress. The great majority sees more benefits than evil in science. The fact that the students recognize the existence of negative consequences does not seem to generate a paralyzing attitude but, instead, induces them to point out the need for a careful consideration of these factors.

With regard to genetics, we have observed that students are relatively well informed about some of the main issues and that they make bold statements on nearly all topics raised, which ranged from transgenic food to the results of the Human Genome Project. This should be considered against the background of the formal science education system, which is frequently inefficient and outdated. This suggests that other factors-different from the school curriculum science-may have a strong influence on the formation of their attitudes. However, this study has not systematically investigated these other factors. Neither do our results allow any significant conclusion concerning possible differences in the attitudes towards genetics among students from different socioeconomic classes.

As we mentioned before, most of the students thought that some applications originating from genetics are useful and should be encouraged, but their support varied, depending on the specific application considered. Although young people-with their own daring capacity - spoke of more advanced experiences with a high degree of naturalness, overall they undertook a balanced analysis of the benefits and the risks that these new uses of science present to society.

As far as medical applications of genetics are concerned, international research has shown that, overall, the public tends to be supportive; yet, at the same time people are strongly opposed to human cloning (Einsiedel, 2000; Gaskell et al., 2000; Priest, 2000). Respondents who argue in favor of placing restrictions on genetic technology frequently tend to think mainly in terms of moral acceptability (Gaskell et al., 1999). The results of our study corroborate these findings. Focus group discussions demonstrated that young people are concerned about ethical and moral issues and that these concerns play a significant role in shaping their attitudes towards the applications of modern biotechnology.

Although the students thought that many applications of genetic manipulation might be useful, many were against encouraging their use. In all cases, the figures for moral acceptance were lower than the values relating to the usefulness of the same techniques. Risk perception and critical positioning were also demonstrated in the focus group discussions. Several potentially negative consequences associated with the application of those techniques were mentioned. In addition, students pointed to the danger of discrimination and increasing social inequality.

With respect to transgenic crops and food, it has been shown that attitudes can range from discrete approval in the United States to rejection by the majority of the European public (Gaskell et al., 1999). In our study, it was clear-both from the questionnaires and from the focus groups - that a significant number of students thought that transgenic food 
could be useful and should be encouraged, but that it also involved risks. Until the risks are better understood, they would prefer not to grow transgenic crops at all. In general, their personal preference was for natural food, and they were strongly in favor of the labeling of transgenic food.

\section{Acknowledgements}

We thank the Brazilian funding agency Capes for the fellowship provided to L. Massarani, and J. Turney for his friendly supervision during L. Massarani's visit to University College London, as part of her Ph.D. program.

\section{Notes}

1 The survey included 2,000 people over the age of 16, sampled throughout the country, and used personal interviews and questionnaires. It took place in July 2001 and the results were published in August of the same year. The estimated confidence interval was 95 percent and the margin of error was 2.2 percentage points.

2 Other researchers collaborated in the wider project for analyzing public understanding of science in Brazil. In particular, we would like to mention I. Magalhães, who participated in the analysis of the press coverage on biotechnology, and R. Lent, who had a key role in the analysis of the university and high school students' attitudes towards general aspects of science and their knowledge of some specific scientific content.

3 These questions related to the following:

- Using biotechnology in the production of foods, for example to increase size and protein level, or to change the taste. (The original question in the Eurobarometer study was "use modern biotechnology in the production of foods, for example to make them higher in protein, keep longer or change the taste.")

- Taking genes from plant species and transferring them to crops, to make them more resistant to insect pests.

- Introducing human genes into bacteria to produce medicines or vaccines. (Eurobarometer question: "introducing human genes in bacteria to produce medicines or vaccines, for example to produce insulin for diabetics.")

- Developing genetically modified animals for laboratory research studies, such as a mouse that has genes that cause it to develop cancer.

- Introducing human genes into animals to produce organs for human transplants, such as into pigs for human heart transplants.

- Using genetic testing to detect diseases that we might have inherited from our parents, such as Down syndrome. (The examples of diseases in the Eurobarometer question were "cystic fibrosis, mucoviscidosis or thalassaemia." We changed this to "Down syndrome" as this is the example of an inheritable disease that people in Brazil are most familiar with.)

- Giving permission for insurance companies to proceed with genetic tests to detect whether people have genetic characteristics that might indicate possible occurrence of certain diseases.

- Genetic manipulation of embryos requested by parents in order to ensure that their baby will not develop genetic diseases.

- Genetic manipulation of embryos requested by parents in order to ensure that their baby will have certain physical characteristics, such as eye or hair color.

4 All discussions have been tape-recorded and fully transcribed. All tapes and transcripts are available for analysis by other researchers.

5 The script included the following questions:

- Do you think the movie shows real life or something that might become real, or is it just science fiction?

- The movie discusses "the perfect genetic constitution." To what extent does our genetic constitution define what we are?

- What role do genes play in human characteristics such as intelligence, violence and criminal tendencies, alcoholism and obesity?

- Is it possible to alter an organism's genetic constitution? If so, what are the positive and negative issues involved?

- What do you think of transgenic food? Would you eat it? 
- How do you perceive human cloning? Are there positive and negative issues involved?

- How far does the independence of scientists and scientific research go?

\section{References}

Alves, I. and Tolmasquim, A. (1987) O que o brasileiro pensa da ciência e da tecnologia?, 2nd edition. Rio de Janeiro and Brasília: MAST and Ministério da Ciência e Tecnologia/CNPq.

Cheveigné, S., Boy, D. and Galloux, J.C. (2002) Les Biotechnologies en débat-Pour une democratie scientifique. Paris: Balland.

Durant, J., Bauer, M. and Gaskell, G. (eds.) (1998) Biotechnology in the Public Sphere. London: Science Museum.

Einsiedel, E. (2000) "Cloning and its Discontents-A Canadian Perspective," Nature Biotechnology 18: 943-4.

Einsiedel, E. and Medlock, J. (2001) "Canada on the Gene Trail," in G. Gaskell and M. Bauer (eds.) Biotechnology 1996-2000: The Years of Controversy, pp. 145-56. London: Science Museum.

Gaskell, G. and Bauer, M. (2001) (eds.) Biotechnology 1996-2000: The Years of Controversy. London: Science Museum.

Gaskell, G., Bauer, M., Durant, J. and Allum, N. (1999) "Worlds Apart? The Reception of Genetically Modified Foods in Europe and the US," Science 285: 384-7.

Gaskell, G., Allum, N., Bauer, M., Durant, J., Allansdottir, A., Bonfadelli, H., Boy, D., de Cheveigné, S., Fjaestad, B., Gutteling, J.M., Hampel, J., Jelsøe, E., Correia Jesuino, J., Kohring, M., Kronberger, N., Midden, C., Hviid Nielsen, T., Przestalski, A., Rusanen, T., Sakellaris, G., Torgersen, H., Twardowski, T. and Wagner, W. (2000) "Biotechnology and the European Public," Nature Biotechnology 18: 935-8.

Human Genetics Commission (2001) Public Attitudes to Human Genetic Information: People's Panel Quantitative Study Conducted for the Human Genetics Commission. London: Human Genetics Commission.

IBOPE (2001) Pesquisa de Opinião Pública sobre Transgênicos, URL: www.greenpeace.com.br/transgenicos/pdf/ pesquisaIBOPE_agosto2001.pdf

IBOPE (2002) Pesquisa de Opinião Pública sobre Transgênicos, URL: www.idec.org.br/files/pesquisa_ transgenicos.pdf

Lewis, J. and Wood-Robinson, C. (2000) “Genes, Chromosomes, Cell Division and Inheritance: Do Students See Any Relationship?," International Journal of Science Education 22: 177-95.

Massarani, L. (2001) "Admirável mundo novo-A ciência, os cientistas e a dupla hélice sob o olhar de estudantes," Unpublished doctoral dissertation, Federal University of Rio de Janeiro, Rio de Janeiro.

Massarani, L., Magalhães, I. and Moreira, I. (2003a) "Quando a ciência vira notícia: Um mapeamento da genética nos jornais diários," Ciência \& Ambiente 26: 141-8.

Massarani, L., Magalhães, I. and Moreira, I. (2003b) "Transgênicos e a mídia impressa no Brasil," in M.F. Barrozo da Costa and M.A.F. Costa (eds) Biossegurança de OGM, pp. 102-21. Rio de Janeiro: Papel Virtual.

National Science Foundation (2002) Science and Engineering Indicators 2002. Division of Science Resources Statistics (April), URL: www.nsf.gov/sbe/srs/seind02/c7/c7s2.htm£attitudes

Oda, L. and Soares, B. (2001) "Biotecnologia no Brasil. Aceitabilidade pública e desenvolvimento econômico," Parcerias Estratégicas 10: 162-73.

Potter, J. and Wetherell, M. (1987) Discourse and Social Psychology: Beyond Attitudes and Behaviour. London: SAGE.

Priest, S. (2000) "US Opinion Divided over Biotechnology?," Nature Biotechnology 18, 939-42.

Shanahan, J., Scheufele, D. and Lee, E. (2002) "The Polls-Trends: Attitudes about Agricultural Biotechnology and Genetically Modified Organism," Public Opinion Quarterly 65: 267-81.

Wertz, D., Sorenson, J. and Heeren, T. (1986) "Clients' Interpretation of Risks Provided in Genetic Counseling," American Journal of Human Genetics 39: 253-64.

\section{Authors}

Luisa Massarani, Dr.Sc., is a science journalist and coordinates the Center of Studies of the Museum of Life (Casa de Oswaldo Cruz, Fiocruz, Brazil). She is also the Latin American coordinator of SciDev.Net (www.scidev.net). Ildeu de Castro Moreira, Dr.Sc., is a physicist, and works at the Institute of Physics and at the Interdisciplinary Group on Epistemology and History of Science and Technology, Federal University of Rio de Janeiro, Brazil.

Correspondence: Luisa Massarani, Av. Brasil, 4365, Manguinhos, CEP 21040-369, Rio de Janeiro, RJ, Brazil; e-mail: lumassa@coc.fiocruz.br 